\title{
Evaluation of relationship between Rotavirus and Coronavirus infections with calf diarrhea by capture ELISA
}

\author{
Ashraf Mayameei • Gholamreza Mohammadi • \\ Samane Yavari • Ehsan Afshari • Arash Omidi
}

Received: 28 May 2009 / Accepted: 24 September 2009/Published online: 16 October 2009

(C) Springer-Verlag London Limited 2009

\begin{abstract}
Rotavirus and Coronavirus are two main causes of severe diarrhea in human infants and many animal species worldwide. Calves up to 3 months old can be affected by these viruses. The importance of these viruses in cattle industry is due to substantial economic loss, treatment costs, and reduced growth rates in beef and dairy calves. Mixed infections caused by Rotavirus and Coronavirus can lead to severe form of diarrhea. In present casecontrol study, 261 samples of healthy and diarrheic calves from farms around Mashhad were collected. These samples were tested by antigen-capture enzyme-linked immunosorbent assay (Bio-X diagnosis kit). The results showed that the prevalence of Rotavirus and Coronavirus infection in diarrheic calves is $26.98 \%$ and $3.17 \%$, respectively. Also,
\end{abstract}

A. Mayameei $(\bowtie)$

Department of Pathobiology, School of Veterinary Medicine,

Ferdowsi University,

Mashhad, Iran

e-mail: mayamee@ferdowsi.um.ac.ir

G. Mohammadi $\cdot$ E. Afshari

Department of Clinical Studies, School of Veterinary Medicine,

Ferdowsi University,

Mashhad, Iran

G. Mohammadi

e-mail: gmohamad@ferdowsi.um.ac.ir

S. Yavari

Graduated DVM student, School of Veterinary Medicine,

Ferdowsi University,

Mashhad, Iran

e-mail: dr81_yavari@yahoo.com

A. Omidi

Department of Animal Sciences, School of Agriculture,

Birjand University,

Birjand, Iran

e-mail: Arashomidi2@gmail.com there was no significant relationship between infection with Rotavirus, Coronavirus, and diarrhea in the studied population.

Keywords Rotavirus · Coronavirus · Calf diarrhea · Capture ELISA

$\begin{array}{ll}\text { Abbreviations } \\ \mathrm{R} & \text { Rotavirus } \\ \mathrm{C} & \text { Coronavirus } \\ \text { ELISA } & \text { Enzyme-linked immunosorbent assay test } \\ \mathrm{BRV} & \text { Bovine rotavirus } \\ \mathrm{BCV} & \text { Bovine coronavirus } \\ \mathrm{Sp} & \text { Specification of ELISA test } \\ \mathrm{Se} & \text { Sensitivity of ELISA test } \\ \mathrm{T}_{\mathrm{p}} & \text { True prevalence }\end{array}$

\section{Introduction}

Calf diarrhea, one of the most widespread diseases, is a complex syndrome with a complex etiopathogenesis, causing important economic losses due to morbidity and mortality, treatment costs, and reduced growth rates in affected calves (Garaicoechea et al. 2006; Reidy et al. 2006). The etiology of this syndrome involves infectious agents (viruses, bacteria, and protozoa) and also noninfectious factors such as herd management, host nutritional, and immunological condition which affect the outcome of the disease (Brussow et al. 1992; Maes et al. 2003; Garaicoechea et al. 2006).

Group A Rotaviruses, as the member of Reoviridae family, have clearly been established as causing significant diarrheal disease in infants and in the young of various 
mammalian and avian species (Brussow et al. 1992; Murphy et al. 1999; Flint et al. 2000; Estes and Kapikian 2001).Group A bovine rotavirus (BRV) is considered the major cause of severe diarrhea in calves worldwide (Garaicoechea et al. 2006). Coronaviruses as the member of Coronaviridae family are associated with economically important diseases in cattle, poultry, pigs, and cats (Lai et al. 2007; Acheson 2007). Bovine coronavirus (BCV) causes diarrhea in both dairy and beef calves worldwide (Radostitis et al. 2007). Since diarrhea in calf and other animals is a great problem which involves economic losses, several diagnostic methods are used to detect enteropathogenic agents. Diagnosis is done through collecting feces of animals suffering from diarrhea by a rectal swab or collecting intestinal contents (Castro and Heuschele 1992) and using laboratory diagnostic tests such as direct electronmicroscopic test, Enzyme-linked immunosorbent assay (ELISA), latex agglutination, polyacrylamide gel electrophoresis, reverse transcription polymerase chain reaction, and also immuno-electron microscopy (Parwani et al. 1992; Radostitis et al. 2007). Among these methods, ELISA using monoclonal antibody, as a sensitive, fast, and inexpensive method could be used for the simultaneous detection of bovine coronavirus, bovine rotavirus group $\mathrm{A}$, and also other enteropathogenic factors in the feces of diarrheic calves (Crouch et al. 1984; Radostitis et al. 2007). In this study, to examine the possible involvement of BRV and BCV in calf diarrhea, a case-control study by using capture ELISA, was performed in dairy farms around Mashhad, Iran.

\section{Materials and methods}

A total of 261 fecal samples from diarrheic (126 samples) and healthy (135 samples) calves of up to 3 months of age were collected from some herds around Mashhad, Iran. The collected samples were kept at $-20^{\circ} \mathrm{C}$ until analyzing. A commercial indirect antigen-capture ELISA kit (Duo Digestive kit (Rotavirus and Coronavirus), Bio K083, Bio-X Diagnostics, Belgium) employing specific monoclonal antibodies was used to detect BRV and BCV in fecal samples. The ELISA procedure was performed according to the manufacturer instruction. After adding stop solution (1 M phosphoric acid), the optical density (OD) of each well was measured at $450 \mathrm{~nm}$. Calculating the net OD of each sample and interpreting the results was performed as described by manufacturer instruction. Briefly, the limit of positivity of each sample was 0.15 . Any sample yielding a net OD value greater than or equal to 0.15 , was considered positive, and less than 0.15 , considered as negative.

The analysis of the results was done with Statistical Package for the Social Sciences software. To evaluate the relationship between two variables: disease and risk factors (the presence of BRV and BCV in calf fecal samples) the chi-square test was applied.

\section{Results}

In this study, a total of 261 samples, 126 from diarrheic and 135 from healthy calves, were analyzed. Rotavirus antigen was detected in 56 and Coronavirus was detected in eight of the total 261 samples (Table 1). The results showed that according to ELISA test, the apparent prevalence of BRV and BCV infection in diarrheic calves, was $26.98 \%$ (34:126) and $3.17 \%$ (4:126), respectively, and also the apparent prevalence of Rotavirus and Coronavirus infection in healthy calves was $17.03 \%$ (23:135) and 2.96\% (4:135), respectively.

By considering $98 \%$ sensitivity and $100 \%$ specificity of ELISA kit for Rotavirus and 95\% sensitivity and 90\% specificity of ELISA kit for Coronavirus, the true prevalence of BRV and BCV in diarrheic and healthy calves was estimated using the "Rogan and Gladen" method (Thrusfield 2005).

Trueprevalence $=\frac{(\text { apparentprevalence }+s p-1)}{(s e+s p-1)}$

(In diarrhetic calves) $T_{p}$ Rota $=\frac{26.98+99-1}{98+100-1}=0.64=64 \%$

(In diarrhetic calves) $T_{p}$ Corona $=\frac{3.17+90-1}{95+90-1}=0.50=50 \%$

(In healthy calves) $T_{p}$ Rota $=\frac{17.03+100-1}{98+100-1}=0.59=59 \%$

(In healthy calves) $T_{p}$ Corona $=\frac{2.96+90-1}{95+90-1}=0.50=50 \%$

According to the results of statistical analysis (chisquare), in spite of higher prevalence of Rotavirus and Coronavirus infection in diarrheic calves, no significant
Table 1 The ELISA results for BRV and BCV antigens in the fecal samples collected from the healthy and diarrheic calves

$B R V$ bovine rotavirus, $B C V$ bovine coronavirus

\begin{tabular}{|c|c|c|c|c|c|}
\hline \multirow[t]{2}{*}{ Calves } & \multirow[t]{2}{*}{ Fecal sample } & \multicolumn{2}{|l|}{ BRV } & \multicolumn{2}{|l|}{$\mathrm{BCV}$} \\
\hline & & Positive & Negative & Positive & Negative \\
\hline With diarrhea & 126 & 34 & 92 & 4 & 122 \\
\hline Healthy & 135 & 23 & 112 & 4 & 131 \\
\hline Total & 261 & 57 & 204 & 8 & 253 \\
\hline
\end{tabular}


Table 2 The ELISA results for BCV and BRV and mixed infection with both BRV and BCV in healthy and diarrheic calves according to age

\begin{tabular}{|c|c|c|c|c|c|c|c|c|}
\hline \multirow[t]{2}{*}{ Age } & \multicolumn{4}{|c|}{ Healthy calves } & \multicolumn{4}{|c|}{ Diarrheic calves } \\
\hline & $\begin{array}{l}\text { No of } \\
\text { samples }\end{array}$ & BRV (\%) & BCV (\%) & $\begin{array}{l}\text { Mixed BRV } \\
\text { and BCV (\%) }\end{array}$ & $\begin{array}{l}\text { No of } \\
\text { samples }\end{array}$ & BRV (\%) & $\mathrm{BCV}(\%)$ & $\begin{array}{l}\text { Mixed BRV } \\
\text { and BCV (\%) }\end{array}$ \\
\hline 1 week & 34 & $8(23)$ & 0 & 0 & 27 & $6(22)$ & 0 & 0 \\
\hline 2 weeks & 28 & $7(25)$ & $1(3.5)$ & $1(3.5)$ & 47 & $17(36)$ & $3(6.3)$ & 1 \\
\hline 3 weeks & 18 & $3(16)$ & $2(11)$ & 0 & 15 & $7(46)$ & $1(6.6)$ & 0 \\
\hline 4 weeks & 18 & $1(5.5)$ & 0 & 0 & 21 & $2(9.5)$ & 0 & 0 \\
\hline Above1 month & 37 & $4(10)$ & $1(2.7)$ & $1(2.7)$ & 16 & $2(12.5)$ & 0 & 0 \\
\hline
\end{tabular}

$B R V$ bovine rotavirus, $B C V$ bovine coronavirus

relationship was established based on comparing healthy and diarrheic calves $(P>0.05)$.

Tables 2 and 3 show the frequency and prevalence of BRV and BCV infection in different ages. Since, the cases of Rotavirus infection were more; it was statistically analyzed in different ages. There was not any significant relationship between Rotavirus infection and disease in different ages of calves in studied population $(P>0.05)$.

\section{Discussion}

Due to spread of intestinal infections outbreak all over the world and the out coming mortality, these infections along with severe diarrhea in many young animals and children are of great importance (Gumusova et al. 2007). In young calves, diarrhea is considered as one of the most important diseases, because the resulting economic loss following mortality, treatment costs, and decrease of growth rate would be detrimental (Maes et al. 2003). Indeed, long-term effects of diarrhea on the health and efficiency of calves cured from clinical courses of the disease may cause more economic loss (Fuente et al. 1998). Rotavirus, Coronavirus, enterotoxigenic Escherichia coli, and Cryptosporidium parvum are four major pathogens accompanied by diarrhea in young calves around the world. These organisms are responsible for most of the intestinal infections (75-90\%) in young calves in the world. Different species of Salmonellae are also of importance in dairy calves (Athanassious et al. 1994; Fuente et al. 1998; Radostitis et al. 2007). To increase the production of each cattle without increasing the number of live stocks, it is important to detect causative factors of diarrhea in calves so as to use, based on this information, the effective preventive methods for decreasing the mortality of calves in the first months of their life (Perez et al. 1998). In this study, along with determining the $\mathrm{BRV}$ and $\mathrm{BCV}$ prevalence in diarrheic calves, a case-control study was performed to examine possible involvement of BRV and BCV in diarrhea in some dairy farms around Mashhad, Iran. Many other studies reported the prevalence of BRV and BCV in scouring calves over the world. The presence of BRV in six and BCV in two samples out of nine fecal samples from diarrheic calves with 10-60 days of age was reported in Sao Paulo, Brazil (Brandao et al. 2007). The other study in Turkey showed the presence of BRV antigen and BCV antigen in diarrheic calves, $41.17 \%$ and $1.96 \%$, respectively. In healthy calves, BRV was detected in $4.08 \%$ and BCV was not detected (Gumusova et al. 2007). In a case-control study in Costa Rica on dairy and beef calves younger than 3 months, by using dot-ELISA test, Rotavirus was detected in $7 \%$ and $2 \%$ of scouring and control calves, respectively, and Coronavirus in $9 \%$ and $1 \%$, respectively. In $25 \%$ of diarrheic calves and $21 \%$ of healthy ones, there were not any infectious factors and viruses were found in infected calves younger than 1 month more predominantly (Perez et al. 1998). In Spain, by using a commercial ELISA kit, Rotavirus was detected in $42.7 \%$ and Coronavirus was found in $7.3 \%$ of fecal samples from diarrheic calves. Mixed infection with Rotavirus and Coronavirus was found in $5.1 \%$ of the total samples of feces, among which, in $2.3 \%$ of fecal samples, the only enteropathogens found were Rotavirus and Coro-
Table 3 The prevalence of $\mathrm{BRV}$ and $\mathrm{BCV}$ infections and mixed infection in all of the 261 fecal samples

$B R V$ bovine rotavirus, $B C V$ bovine coronavirus

\begin{tabular}{llll}
\hline Age & Prevalence of BRV (\%) & Prevalence of BCV $(\%)$ & Prevalence ofmix(\%) \\
\hline 1 week & 23 & - & - \\
2 weeks & 32 & 5 & 2 \\
3 weeks & 30 & 9 & - \\
4 weeks & 8 & - & - \\
Above 1 month & 11 & 2 & 1 \\
\hline
\end{tabular}


navirus (Fuente et al. 1998). In another study on 218 fecal samples from diarrheic dairy calves, 1-30 days old, rotaviral infection was detected in $46.2 \%, 45.6 \%, 33.8 \%$, and $48.3 \%$ of the calves in the respective age groups of 1-7, 8-14, 1521 , and 22-30 days. There was no significant differences in the detection rate of rotaviral infection among calves on the different age groups (Garcia et al. 2000).The other study reported the presence of BRV in $10 \%$ of fecal samples of dairy calves younger than 3 months in Costa Rica (Hird et al. 1990). In a study in Switzerland, the prevalence of bovine rotavirus and Coronavirus in infected calves with age of 121 days, were $58.7 \%$ and $7.8 \%$, respectively (Uhde et al. 2008). In Iran, the presence of Rotavirus, Coronavirus, and other enteropathogens in feces of calves were studied in farms in Tehran (Kargar et al. 1981; Keyvanfar et al. 2001), Arak (Qaem Maghami et al. 2000), northwest of Iran (Khalili et al. 2006), and Khouzestan (Mayameei et al. unpublished). In the present study, by using antigen-capture ELISA test, the prevalence of BRV in diarrheic and healthy fecal samples was $26.98 \%$ and $17.03 \%$, respectively, and the rate of Coronavirus prevalence in diarrheic samples was $3.17 \%$ and $2.96 \%$ in healthy ones.

The determined rate of prevalence for Rotavirus in diarrheic fecal samples in this study $(26.98 \%)$ is rather consistent with the results of Kargar Moakher (31.74\%), Qaem Maghami (34\%), and Keyvanfar studies (28.8\%); but in studies by Hird (10\%), Perez(7\%), Gumosuva (41.7\%), Foente $(42.7 \%)$, Garcia(43.65\%), Uhde (58.7\%), and Mayameei (48\%), there was significant difference in determined rate of prevalence for Rotavirus in diarrheic samples. The determined rate of prevalence for Coronavirus in diarrheic feces in this study (3.17\%), in some cases, has considerable difference with studies by Gumosuva (1.96\%), Perez (9\%), Foente (7.3\%), Garcia (20.4\%), Uhde (7.8\%), Qaem Maghami (34\%), and Khalili (12.03\%). The number of samples and the range of age for the studied calves, sensitivity of the employing detection method, season of sampling, management and hygienic situation of the ranches, nutritional situation of calves, rainfall and humidity rate, and other factors were not identical in these studies, which all of them can influence on the results. Specially, in cold seasons, increase of pollution and presence of sensitive calves and crowding would cause the prevalence rate of rotaviral and coronaviral infection to increase. The range of age in which sampling is performed and also the kind of husbandry (dairy or beef) surely affect the prevalence. In this study, although infection with Rotavirus and Coronavirus in diarrheic calves was more than that of healthy ones, there was no significant relationship between BRV and BCV infection with diarrhea based on statistical analysis. So the role of other enteropathogens in the occurrence of calf diarrhea could be considered in this study. It is also possible that some healthy calves, which were recognized positive for Rotavirus and
Coronavirus in ELISA test, had been in the beginning of the disease process without any clinical signs of diarrhea. Although, according to the short incubation period of diarrhea caused by BRV and BCV, this would be an unlikely event. By considering the prevalence of BRV and $\mathrm{BCV}$ in diarrheic calves in different age groups (Table 2), it is concluded that the rate of BRV infection in third week is higher than the other age groups and the lower rate of BRV infection is related to age older than 1 month. This could be attributed to the presence of colostrum antibodies and strong local immunity, particularly in the first week and almost the second week which decrease the occurrence of rotaviral diarrhea in the first 2 weeks. After decreasing of local passive immunity and the occurrence of natural rotaviral infections in the third and fourth weeks of life and subsequent activation of local host immunity, the rate of viral infections drop in calves older than 1 month.

As a result, it is suggested that along with management practices and promoting the immunity level in calves to decrease the rate of infection by $\mathrm{BRV}$ and $\mathrm{BCV}$, it is necessary to analyze the fecal samples for the presence of other enteropathogens such as E. coli and Cryptosporidium.

\section{References}

Acheson NH (2007) Fundamentals of molecular virology. Wiley, New York, pp 202-211

Athanassious R, Marsolais G, Assaf R, Dea S, Descoteaux JP, Dulude S, Montpetit C (1994) Detection of bovine coronavirus and type A Rotavirus in neonatal calf diarrhea and winter dysentery of cattle in Quebec: evaluation of three diagnostic methods. Can Vet J 35:163-169

Brandao PE, Villarreal LYB, de Souza SLP, Richtzenhain LJ, Jerez JA (2007) Mixed infections by bovine coronavirus, Rotavirus and Cryptosporidium parvum in an outbreak of neonatal diarrhea in beef cattle. Arq Inst Biol Sao Paulo 74:33-34

Brussow H, Nakagomi O, Gerna G, Eichhorn W (1992) Isolation of an avian-like group A Rotavirus from a calf with diarrhea. J Clin Microbiol 30:67-73

Castro AE, Heuschele WP (1992) Veterinary diagnostic virology. Mosby-Year Book, St. Louis, pp 92-96

Crouch CF, Raybould TGF, Acres SD (1984) Monoclonal antibody capture enzyme linked immunosorbent assay for detection of bovine enteric coronavirus. J Clin Microbiol 19 (3):388-393

Estes MK, Kapikian AZ (2007) Rotaviruses. In: Knipe DM, Howley PM (eds) Fields virology. Lippincott Wiliams and Wilkins, Philadelphia, pp 1917-1974

Flint SJ, Enquist LW, Krug RM, Racaniello VR, Skalka AM (2000) Principles of virology, molecular biology, pathogenesis and control. ASM Press, Washington, D.C., p 663

Fuente R, Garcia A, Ruiz-Santa-Quiteria JA, Luzon M, Cid D, Garcia S, Orden J, Gomez-Bautista M (1998) Proportional morbidity rates of enteropathogens among diarrheic dairy calves in Central Spain. Prev Vet Med 36:145-152

Garaicoechea L, Bok K, Jones LR, Combessies G, Odeon A, Fernandez F, Parreno V (2006) Molecular characterization of bovine rotavirus circulating in beef and dairy herds in 
Argentina during a 10-year period (1994-2003). Vet Microbiol 118:1-11

Garcia A, Ruiz-Santa-Quiteria JA, Orden JA, Cid D, Sanz R, Gomes-Bautista M, Fuente R (2000) Rotavirus and concurrent infections with other enteropathogens in neonatal diarrheic dairy calves in Spain. Comp Immunol Microbiol Infect Dis 23:175183

Gumusova SO, Yazici Z, Albayrak H, Meral Y (2007) Rotavirus and Coronavirus prevalence in healthy calves and calves with diarrhea. Med Wet 63(1):62-64

Hird D, Perez E, Caballero M, Rodriguez L, Velazquez J (1990) Identification of selected disease agents from calves on Costa Rican tropical cloud-forest dairy farms. Prev Vet Med 9:221231

Kargar R, Yoosefi Y, Shahrabadi MS, Khodashenas M, Heidarzade B (1981) Diarrhea in calves: diagnosis and incidence around Tehran. Archive de I'institut Razi 32:91-99

Keyvanfar H, Ghorbanpour M, Seifi Abad Shapouri MR (2001) A survey on prevalence of rotaviral diarrhea in dairy calves in Tehran region and determination of serotypes. J Vet Med University of Tehran 56:3-11

Khalili M, Morshedi A, Keyvanfar H, Hemmatzadeh F (2006) Detection of bovine coronavirus by RT-PCR in field study. Veterinarski Arh 76(4):291-296

Lai MMC, Perlman S, Anderson LJ (2007) Coronaviridae. In: Knipe DM, Howley PM (eds) Fields virology. Lippimcott Wiliams and Wilkins, Philadelphia, pp 1307-1333
Maes RK, Grooms DL, Wise AG, Han C, Ciesicki V, Hanson L, Vickers MJ, Kanitz C, Holland R (2003) Evaluation of a human group A Rotavirus assay for on-site detection of bovine rotavirus. J Clin Microbiol 41:290-294

Murphy, F.A., Gibbs, E. Paul J., Horzinek, M.C., Studdert, M.J. (1999) Veterinary Virology 3rd edition. New York: Academic Press. 402-404, 495-500

Parwani AV, Rosen BI, Flores J, McCrae MA, Gorziglia M, Saif LJ (1992) Detection and differentiation of bovine group A Rotavirus serotypes using polymerase chain reaction-generated probes to the VP7 gene. Jour Vet Diag Med 4:148-158

Perez E, Kummeling A, Janssen M, Jimenez C, Alvarado R, Caballero M, Donado P, Dwiner R (1998) Infectious agents associated with diarrhea of calves in the canton of Tilaran, Costa Rica. Prev Vet Med 33:195-205

Radostitis OM, Gay CC, Hinchcliff KW, Constable PD (2007) Veterinary Medicine, A textbook of the diseases of cattle, horses, sheep, pigs, and goats, 10th edn. Saunders-Elsevier, Philadelphia, pp 1286-1296

Reidy N, Lennon G, Fanning S, Power E, O'Shea H (2006) Molecular characterization and analysis of bovine rotavirus strains circulating in Ireland 2002-2004. Vet Microbiol 117:242-247

Thrusfield M (2005) Veterinary epidemiology, 3rd edn. Blackwell Science, Oxford, pp 281-285

Uhde F, Kaufmann T, Sager H, Albini S, Zanoni R, Schelling E, Meylan M (2008) Prevalence of four enteropathogens in the young diarrheic dairy calves in Switzerland. Vet Rec 163(12):362-6 